International Journal of Electrical and Power Engineering 12 (1): 1-5, 2018

ISSN: $1990-7958$

(C) Medwell Journals, 2018

\title{
Improving the Accuracy of the DC-DC Converter using Disturbance Estimator
}

\author{
Muhanad D. Almawlawe \\ Al-Diwaniya Governorate, Engineering College, \\ University of Al-Qadisiyah, Diwaniyah, Republic of Iraq
}

\begin{abstract}
This study discusses the design of a discrete-time controller for self-tuning that takes into consideration random disturbances that effect on the boost DC-DC, this controller implements the Generalized Minimum Variance Control (GMV) with disturbance estimator. The GMV method is based on the input/output measurements and holds the output voltage as stable as possible in spite of the parameters variations while the disturbance estimator increases the accuracy. Finally, we verify the control method by digital simulation to show the performance and the effectiveness of the controller added to the boost DC-DC converter.
\end{abstract}

Key words: Generalized Minimum Variance Control (GMVC), nonlinear systems, state-space, boost, converter, estimator, disturbance

\section{INTRODUCTION}

In modern devices such as industrial applications (spacecraft power systems, DC motor drives, telecommunication equipment) or personal applications (PCs, office equipment, electrical appliance), the need for power supplies with high-performance of regulation in practice is increasing because of the stochastic disturbances, so, the control system must be more reliable, stable and economic. The Minimum Variance (MV) method is one of these methods which can be used to design such control systems because of the advantages such as its implementation in both cases when the system parameters are known or unknown, it can follow the changes of the system parameters, taking into account the disturbances in practical cases, straightforward method and is not time-consuming, it remarkably decreases the deviation of the controlled signal around its desired value. The minimum variance control was first introduced by Astrom assuming the linear plant was a minimum phase and later derived the MV controller for processes that could be non-minimum phase (Astrom, 1970; Astrom et al., 1977). The Generalized Minimum Variance (GMV) algorithm was discussed by Clarke and Hastings-James (1971) to control non-minimum phase systems. It is an expansion of the minimum variance algorithm considered by Astrom, this later assumed for linear plant and minimum phase but it is unstable for the non-minimum phase process, the control law modified by Clarke and Hastings-James (1971) guarantee that the plant can be stable on non-minimum phase process, although when the power weighting tended to zero the control law reverted to the initial algorithm of Astrom (Grimble, 1981, 1988).
Boost DC-DC converter: The DC-DC converters are nonlinear systems which is the consequence of the use of semiconductor devices (switches), parasitic capacitance and inductance, another source of this non-linearity comes from the control circuits comprise of comparators, PWM, internal and external disturbances (Deane and Hamill, 1990). Therefore, the system cannot be easily solved analytically using Laplace transform. Many papers have discussed the methods that deal with these converters in this study a digital controller based on generalized minimum variance control with the disturbance estimator.

The complete concept of the boost DC-DC converter is shown in Fig. 1 which explains a power electronic system which is consists of an energy source an electrical load, a power electronic circuit and a control circuit. The power electronic circuit contains switches, lossless energy storage elements. The control circuit takes information from the source, load and designer and then determine how the switches operate to achieve the desired conversion. The control circuits are usually built up with conventional low-power analog and digital electronics (Hauke, 2010).

The boost DC-DC converters are used in applications where the required output voltage needed to be higher than the source voltage. The control of this type of DC-DC converters is harder than the Buck type where the output voltage is less significant than the voltage of origin. The difficulties in the control of boost converters are due to the non-minimum phase structure, i.e., since, the control input shows both in voltage and current equations from the power view of boost type converters are harder than buck type (Hwu et al., 2012). 


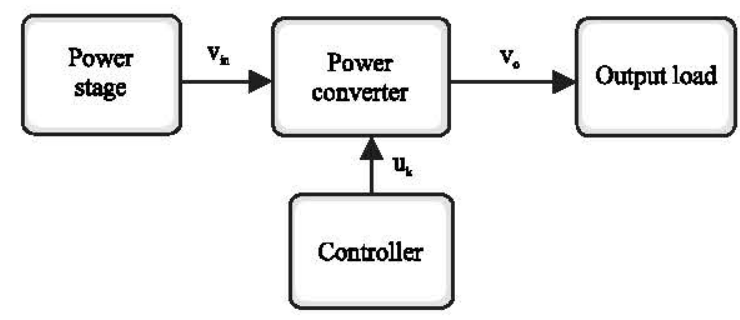

Fig. 1: Block diagram of a characteristic power supply

To overcome the nonlinearity, the input voltage and load variations of the DC-DC converter, different control algorithms are applied to regulate this converter to ensuring stability in any operating condition, a robust output voltage with fast transient response. In this study, the Generalized Minimum Variance Control (GMVC) method is considered with disturbance estimator.

\section{MATERIALS AND METHODS}

Digital controller design: Establishing the mathematical model for the boost DC-DC converter is the first step of the design procedure using Fig. 2 which illustrates the ideal boost DC-DC converter, working in Continuous Conduction Mode (CCM), the state-space model of the DC-DC boost converter in the controllable canonical form is concluded (Sira-Ramirez and Silva-Ortigoza, 2006):

$$
A=\left[\begin{array}{cc}
0 & 1 \\
0 & -\frac{1}{R_{L} C}
\end{array}\right], B=\left[\begin{array}{c}
0 \\
\frac{B\left(v_{i}-v_{0}\right)}{L C}
\end{array}\right], C=\left[\begin{array}{ll}
1 & 0
\end{array}\right]
$$

Improving the accuracy of the DC-DC converter using disturbance estimator:

Where:

$$
\mathrm{W}_{\mathrm{bc}}=\frac{\frac{\beta\left(\mathrm{V}_{\mathrm{i}}-\mathrm{V}_{0}\right)}{\mathrm{LC}}}{\mathrm{s}^{2}+\frac{1}{\mathrm{R}_{\mathrm{L}} \mathrm{C}} \mathrm{s}}
$$

$\mathrm{L} \quad=$ Inductance

$\mathrm{C}=$ Capacitance

$\mathrm{R}_{\mathrm{L}} \quad=$ Load resistance

$\mathrm{v}_{\mathrm{i}} \quad=$ Input voltage

$\beta=$ Sensor gain $V_{\text {ref }}$

$\mathrm{v}_{0}$ and $\beta \mathrm{v}_{0}=$ The reference, output and sensed output voltage

Equation 2 represents the transfer function of ideal DC-DC boost converter working in continuous conduction mode. The linear dynamic system with SISO can be represented as:

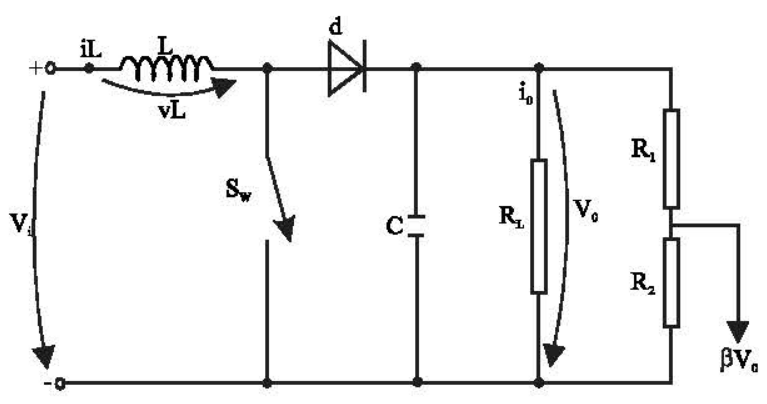

Fig. 2: Ideal boost DC-DC converter

$$
\begin{aligned}
& \dot{x}=A x+B u+d f \\
& y=C x
\end{aligned}
$$

where, $x=\left[x_{1}, x_{2}, \ldots, x_{n}\right]^{T} \in R^{n}$ which represents $R$ state-vector, $\mu \epsilon \mathrm{s}$ the input of the system under control, $\mathrm{f} \epsilon$ Rexternal disturbances, $Y \in R$ the output of the scheme $\mathrm{n}$ - is the order of the system and $\mathrm{x}(\mathrm{t}) \in \mathrm{R}^{\mathrm{n}}$ is a state-space vector, $\bar{u}(t) \in R$ is input, $y(t)$ is output. Now we write the discrete-time representation of the model (Eq. 1) in the following form:

$$
\begin{aligned}
& \mathrm{x}_{\mathrm{k}+1}=\mathrm{Fx}_{\mathrm{k}}+\mathrm{Gu}_{\mathrm{k}}+\mathrm{h}_{\mathrm{k}} \\
& \mathrm{y}_{\mathrm{k}}=\mathrm{Cx}_{\mathrm{k}}
\end{aligned}
$$

Here:

$$
\begin{aligned}
& F=e^{A T}, G=\int_{0}^{T} e^{A \lambda} B d \lambda \\
& \left.h_{k}=\int_{0}^{T} e^{A \lambda} d f(k+1) T-\lambda\right) d \lambda
\end{aligned}
$$

The mathematical model of the converter system in discrete time domain (Mitic, 2006):

$$
\mathrm{y}_{\mathrm{k}}=\frac{\mathrm{z}^{-1} \mathrm{~B}\left(\mathrm{z}^{-1}\right)}{\mathrm{A}\left(\mathrm{z}^{-1}\right)} \mathrm{u}_{\mathrm{k}}+\frac{\mathrm{z}^{-1} \mathrm{D}\left(\mathrm{z}^{-1}\right)}{\mathrm{A}\left(\mathrm{z}^{-1}\right)} \mathrm{h}_{\mathrm{k}}
$$

Where:

$$
\begin{gathered}
A\left(z^{-1}\right)=z^{-n} \operatorname{det}(z I-F) \\
B\left(z^{-1}\right)=z^{-n+1} C \operatorname{adj}(z I-F) G \\
D\left(z^{-1}\right)=z^{-n+1} C \operatorname{adj}(z I-F)
\end{gathered}
$$

where, $\mathrm{z}^{-1}$ is the unit delay, i.e., $\mathrm{z}^{-1}=\mathrm{e}^{-\mathrm{sT}} \mathrm{s}$ denotes a complex variable $(\mathrm{k})(\mathrm{kT})$ and:

$$
\begin{aligned}
& \mathrm{A}\left(\mathrm{z}^{-1}\right)=\mathrm{A}_{\mathrm{n}}\left(\mathrm{z}^{-1}\right)+\Delta \mathrm{A}\left(\mathrm{z}^{-1}\right) \\
& \mathrm{B}\left(\mathrm{z}^{-1}\right)=\mathrm{B}_{\mathrm{n}}\left(\mathrm{z}^{-1}\right)+\Delta \mathrm{B}\left(\mathrm{z}^{-1}\right)
\end{aligned}
$$




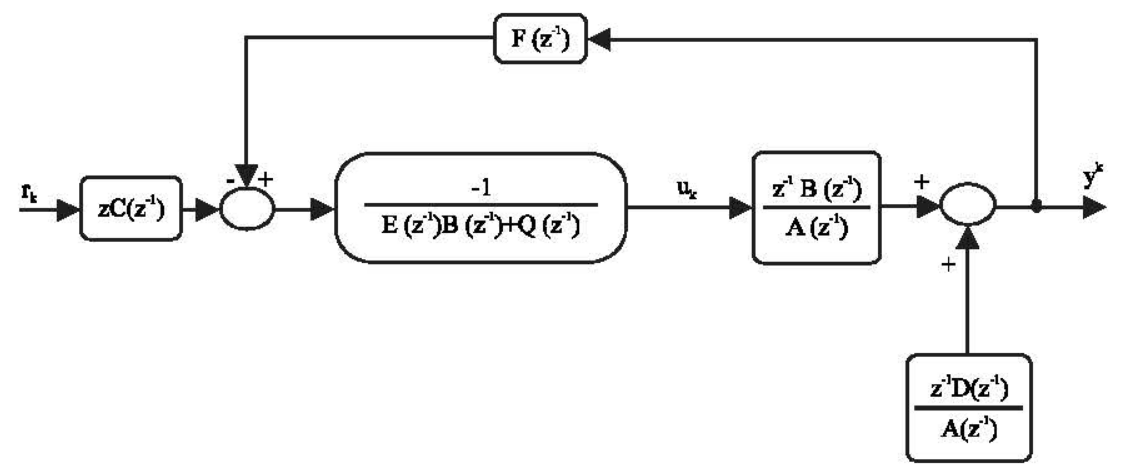

Fig. 3: Block diagram of the GMV control with disturbance estimator

$\operatorname{An}\left(\mathrm{z}^{-1}\right), \mathrm{Bn}\left(\mathrm{z}^{-1}\right), \Delta \mathrm{A}\left(\mathrm{z}^{-1}\right), \Delta \mathrm{B}\left(\mathrm{z}^{-1}\right)$ represent the polynomials with nominal and perturbed values of boost converter parameters, respectively.

The generalized minimum variance: The goal of using such method is to establish a control law $\mathrm{u}_{\mathrm{k}}$ (Mitic and Milosavljevic, 2004):

$$
u_{k}=-\frac{1}{E\left(z^{-1}\right) B\left(z^{-1}\right)+Q\left(z^{-1}\right)}\left[F\left(z^{-1}\right) y_{k}-C\left(z^{-1}\right) r_{k+1}\right]
$$

where, $E\left(z^{-1}\right)$ and $F\left(z^{-1}\right)$ are the polynomials obtained as the solutions of the Diophantine equation:

$$
E\left(z^{-1}\right) A\left(z^{-1}\right)+z^{-1} F\left(z^{-1}\right)=C\left(z^{-1}\right)
$$

Here, $\mathrm{C}\left(\mathrm{z}^{-1}\right)$ is a polynomial with all zeros inside the unit disk. This control law will minimize the variance of the variable:

$$
\mathrm{S}_{\mathrm{k}+1}=\mathrm{C}\left(\mathrm{z}^{-1}\right)\left(\mathrm{y}_{\mathrm{k}+1}-\mathrm{r}_{\mathrm{k}+1}\right)+\mathrm{Q}\left(\mathrm{z}^{-1}\right) \mathrm{u}_{\mathrm{k}}
$$

$\mathrm{r}_{\mathrm{k}+1}$ is a known reference input is chosen as:

$$
Q\left(z^{-1}\right)=Q_{1}\left(1-z^{-1}\right)
$$

By substituting Eq. 11 in Eq. 6, taking into account (Eq. 12), we get $\mathrm{S}_{\mathrm{k}+1}$ form:

$$
\mathrm{S}_{\mathrm{k}+1}=\mathrm{E}\left(\mathrm{z}^{-1}\right) \mathrm{D}\left(\mathrm{z}^{-1}\right) \mathrm{h}_{\mathrm{k}}=\mathrm{O}(\mathrm{T})
$$

In the steady state (when $\mathrm{k} \rightarrow \infty$ and $\mathrm{z}=1$ ), the system output is defined by:

$$
\mathrm{y}_{\infty}=\mathrm{r}_{\infty}+\frac{\mathrm{S}_{\infty}}{\mathrm{C}(1)}
$$

As $\mathrm{S}_{\mathrm{k}+1}$ is $\mathrm{O}(\mathrm{T})$ in accordance with (Eq. 16), the steady-state accuracy will be within $\mathrm{O}(\mathrm{T}) / \mathrm{C}(\mathrm{Eq} .1)$ boundaries.
The generalized minimum variance with disturbance estimator: In this case, the control law now is:

$$
\begin{aligned}
& \mathrm{u}_{\mathrm{k}}=-\frac{1}{\mathrm{E}\left(\mathrm{z}^{-1}\right) \mathrm{B}\left(\mathrm{z}^{-1}\right)+\mathrm{Q}\left(\mathrm{z}^{-1}\right)} \\
& {\left[\mathrm{F}\left(\mathrm{z}^{-1}\right) \mathrm{y}_{\mathrm{k}}-\mathrm{C}\left(\mathrm{z}^{-1}\right) \mathrm{r}_{\mathrm{k}+1}+\mathrm{E}\left(\mathrm{z}^{-1}\right) \mathrm{D}\left(\mathrm{z}^{-1}\right) \mathrm{h}_{\mathrm{k}-1}\right]}
\end{aligned}
$$

To avoid the need to know the system state coordinates, we use the disturbance estimator obtained from (Eq. 6) in the form of:

$$
\mathrm{D}\left(\mathrm{z}^{-1}\right) \mathrm{h}_{\mathrm{k}-1}=\mathrm{A}\left(\mathrm{z}^{-1}\right) \mathrm{y}_{\mathrm{k}}-\mathrm{B}\left(\mathrm{z}^{-1}\right) \mathrm{u}_{\mathrm{k}-1}
$$

Substituting Eq. 17 in Eq. 6 and taking in account (Eq. 12) will yields:

$$
\begin{aligned}
& \mathrm{S}_{\mathrm{k}+1}=\mathrm{E}\left(\mathrm{z}^{-1}\right) \mathrm{D}\left(\mathrm{z}^{-1}\right)\left(\mathrm{h}_{\mathrm{k}}-\mathrm{h}_{\mathrm{k}-1}\right) \\
& \mathrm{h}_{\mathrm{k}}-\mathrm{h}_{\mathrm{k}-1}=\int_{0}^{\mathrm{T}} \mathrm{e}^{\mathrm{A} \lambda} \mathrm{d} \int_{\mathrm{kT}-\lambda}^{(\mathrm{k}+1) \mathrm{T}-\lambda} \dot{\mathrm{f}}(\sigma) \mathrm{d} \sigma \mathrm{d} \lambda=\mathrm{O}\left(\mathrm{T}^{2}\right)
\end{aligned}
$$

Here, the precision is $O\left(\mathrm{~T}^{2}\right) \mathrm{f}(\mathrm{t})$ if is limited. Therefore, the system accuracy in the steady -state will be within $O$ $\left(\mathrm{T}^{2} / \mathrm{C}\right.$ (Eq. 1) he boundaries. The block diagram of the generalized minimum variance control with disturbance estimator is given in Fig. 3.

In other words using GMV with disturbance estimator gives better accuracy than when applied the same controller without estimators which means that it will provide zero error tracking the reference input signal in the case of the operation of step disturbances while in case when the disturbances in the form of tilting signal this error to be $\mathrm{O}\left(\mathrm{T}^{2}\right)$ limits. The implementation of the

disturbance estimator with GMV has the same effect such as adding additional integral member in the front of this controller knowing that:

$$
\mathrm{D}\left(\mathrm{z}^{-1}\right) \mathrm{h}_{\mathrm{k}-1}=\mathrm{A}\left(\mathrm{z}^{-1}\right) \mathrm{y}_{\mathrm{k}}-\mathrm{B}\left(\mathrm{z}^{-1}\right) \mathrm{u}_{\mathrm{k}-1}
$$




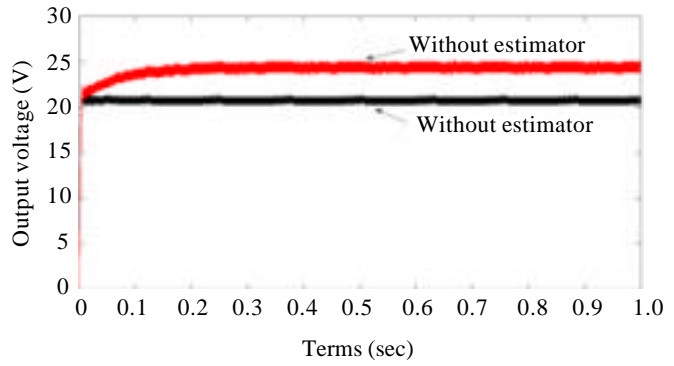

Fig. 4: Output voltage with and without disturbance estimator for $\mathrm{R}_{\mathrm{L}_{\text {_min }}}$

which represents the equation of the disturbance estimator delayed for one sampling time, substituting Eq. 20 in Eq. 17 gives:

$\mathrm{u}_{\mathrm{k}}=-\frac{\left[\mathrm{F}\left(\mathrm{z}^{-1}\right) \mathrm{y}_{\mathrm{k}}-\mathrm{C}\left(\mathrm{z}^{-1}\right) \mathrm{r}_{\mathrm{k}+1}+\mathrm{E}\left(\mathrm{z}^{-1}\right) \mathrm{A}\left(\mathrm{z}^{-1}\right) \mathrm{y}_{\mathrm{k}}-\mathrm{E}\left(\mathrm{z}^{-1}\right) \mathrm{B}\left(\mathrm{z}^{-1}\right) \mathrm{u}_{\mathrm{k}-1}\right]}{\mathrm{E}\left(\mathrm{z}^{-1}\right) \mathrm{B}\left(\mathrm{z}^{-1}\right)+\mathrm{Q}\left(\mathrm{z}^{-1}\right)}$

Multiplying Eq. 21 with $\mathrm{E}\left(\mathrm{z}^{-1}\right) \mathrm{B}\left(\mathrm{z}^{-1}\right)+\mathrm{Qz} \mathrm{z}^{-1}$ and putting the member on the right side of the equation, taking in account (Eq. 14), we have:

$$
\mathrm{u}_{\mathrm{k}}=-\frac{\left[\left(\mathrm{F}\left(\mathrm{z}^{-1}\right)+\mathrm{E}\left(\mathrm{z}^{-1}\right) \mathrm{A}\left(\mathrm{z}^{-1}\right)\right) \mathrm{y}_{\mathrm{k}}-\mathrm{C}\left(\mathrm{z}^{-1}\right) \mathrm{r}_{\mathrm{k}+1}\right]}{\left(\mathrm{E}\left(\mathrm{z}^{-1}\right) \mathrm{B}\left(\mathrm{z}^{-1}\right)+\mathrm{Q}_{1}\left(\mathrm{z}^{-1}\right)\right)\left(1-\mathrm{z}^{-1}\right)}
$$

This control law doesn't differ from Eq. 11 only by the integral member $1 /\left(1-z^{-1}\right)$ and using an algorithm (Eq. 22) on the system (Eq. 6) will give the same results on the system accuracy.

\section{RESULTS AND DISCUSSION}

In this study, we implement MATLAB/SImulink as software to verify the proposed method of control, i.e., GMVC with disturbance estimator for boost DC-DC converter, the values of the parameters in the system are given in Table 1, in the simulation process we consider the following information:

- Sampling frequency $\mathrm{T}=1 \mathrm{msec}$

- Reference voltage $\mathrm{V}_{\text {ref }}=2.4 \mathrm{~V}$

- $\mathrm{f}_{0}=0.9132, \mathrm{f}_{1}=-0.6956$

- $\mathrm{A}\left(\mathrm{z}^{-1}\right)=1-1.9802 \mathrm{z}^{-1}+0.9802 \mathrm{z}^{-2}$

- $\mathrm{B}\left(\mathrm{z}^{-1}\right)=1.3515+1.3425 \mathrm{z}^{-1}$

- $C\left(z^{-1}\right)=1-11.067 z^{-1}+0.2846 z^{-2}$

The waveforms of the output voltage $\mathrm{V}_{0}$ are shown in Fig. 4-6, the simulation consider different values of the load resistance.

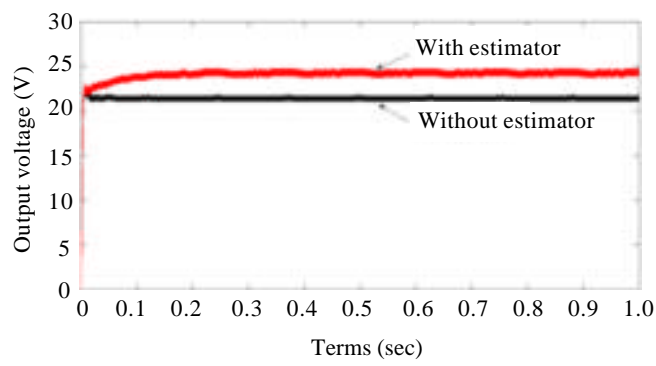

Fig. 5: Output voltage with and without disturbance estimator for $\mathrm{R}_{\mathrm{L}}$

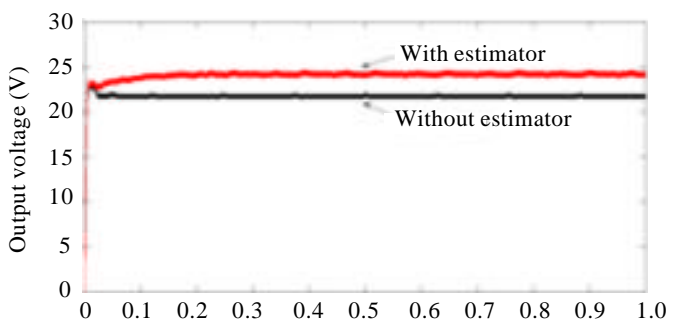

Fig. 6: Output voltage with and without disturbance estimator for $\mathrm{R}_{\mathrm{L}_{\text {_min }}}$

\section{CONCLUSION}

This study presents digital controller using generalized minimum variance method with disturbance estimator which increase the accuracy. The whole procedure is based on the input/output measurements in the cases where external disturbances and parameter variations are acting on the closed-loop dynamics, taking into account that the generalized minimum variance components of control algorithms may be considered as the counterpart of the equivalent control. Using GMVC with disturbance estimator enable many advantages such as: reaching an accuracy of $\mathrm{O}\left(\mathrm{T}^{2}\right)$, suppression of the chattering phenomenon through the discrete-time integrator, theoretically if $\mathrm{T} \rightarrow 0$, the discrete-time integrator tends to the continuous time analog and the control becomes free of chattering (Bartolini et al., 1998).

\section{REFERENCES}

Astrom, K.J., 1970. Introduction to Stochastic Control Theory. Academic Press, London, UK., ISBN: 9780120656509, Pages: 299.

Astrom, K.J., U. Borisson, L. Ljung and B. Wittenmark, 1977. Theory and applications of self-tuning regulators. Autom., 13: 457-476.

Bartolini, G., A. Ferrara and E. Usani, 1998. Chattering avoidance by second-order sliding mode control. IEEE Trans. Autom. Control, 43: 241-246. 
Clarke, D.W. and R. Hastings-James, 1971. Design of digital controllers for randomly disturbed systems. Proc. Inst. Electr. Eng., 118: 1503-1506.

Deane, J.H. and D.C. Hamill, 1990. Instability, subharmonics and chaos in power electronic systems. IEEE. Trans. Power Electr., 5: 260-268.

Grimble, M.J., 1981. A control weighted minimum-variance controller for non-minimum phase systems. Int. J. Control., 33: 751-762.

Grimble, M.J., 1988. Generalized minimum variance control law revisited. Optimal Control Appl. Methods, 9: 63-77.

Hauke, B., 2010. Basic calculation of a boost converter's power stage. M.Sc Thesis, Texas Instruments, Dallas, Texas.
Hwu, K.I., W.C. Tu and C.F. Chuang, 2012. A step-up converter based on charge pump and dual boost. Intl. Rev. Electr. Eng., 7: 4814-4821.

Mitic, D. and C. Milosavljevic, 2004. Sliding mode-based minimum variance and generalized minimum variance controls with $\mathrm{O}(\mathrm{T} 2)$ and $\mathrm{O}(\mathrm{T} 3)$ accuracy. Electr. Eng., 86: 229-237.

Mitic, D., 2006. [Digital variable structure system based on input-output model]. Ph.D. Thesis, Faculty of Electronic Engineering, University of Nis, Nis, Serbia. (In Serbian)

Sira-Ramirez, H.J. and R. Silva-Ortigoza, 2006. Control Design Techniques in Power Electronics Devices. Springer, Berlin, Germany, ISBN-13:9781846284588, Pages: 421. 